\title{
How equitable are the distributions of the physical activity and accessibility benefits of bicycle infrastructure?
}

\author{
Christopher Standen ${ }^{1,2^{*}} \mathbb{D}$, Melanie Crane ${ }^{3}$, Stephen Greaves ${ }^{4}$, Andrew T. Collins ${ }^{4}$ and Chris Rissel ${ }^{3}$
}

\begin{abstract}
Background: Cycling for transport provides many health and social benefits - including physical activity and independent access to jobs, education, social opportunities, health care and other services (accessibility). However, some population groups have less opportunity to reach everyday destinations, and public transport stops, by bicycle - owing in part to their greater aversion to riding amongst motor vehicle traffic. Health equity can therefore be improved by providing separated cycleway networks that give more people the opportunity to access places by bicycle using traffic-free routes. The aim of this study was to assess the health equity benefits of two bicycle infrastructure development scenarios - a single cycleway, and a complete network of cycleways - by examining the distributions of physical activity and accessibility benefits across gender, age and income groups.

Methods: Travel survey data collected from residents in Sydney (Australia) were used to train a predictive transport mode choice model, which was then used to forecast the impact of the two intervention scenarios on transport mode choice, physical activity and accessibility. The latter was measured using a utility-based measure derived from the mode choice model. The distributions of the forecast physical activity and accessibility benefits were then calculated across gender, age and income groups.
\end{abstract}

Results: The modelled physical activity and accessibility measures improve in both intervention scenarios. However, in the single cycleway scenario, the benefits are greatest for the male, high-income and older age groups. In the complete network scenario, the benefits are more equally distributed. Forecast increases in cycling time are largely offset by decreases in walking time - though the latter is typically low-intensity physical activity, which confers a lesser health benefit than moderate-intensity cycling.

Conclusions: Separated cycleway infrastructure can be used to improve health equity by providing greater opportunities for transport cycling in population groups more averse to riding amongst motor vehicle traffic. Disparities in the opportunity to access services and economic/social activities by bicycle - and incorporate more physical activity into everyday travel - could be addressed with connected, traffic-free cycleway networks that cater to people of all genders, ages and incomes.

Keywords: Health equity, Physical activity, Accessibility, Bicycle

*Correspondence: c.standen@unsw.edu.au

${ }^{1}$ Centre for Primary Health Care and Equity, School of Population Health, University of New South Wales, Kensington, NSW 2052, Australia

Full list of author information is available at the end of the article

\section{Background}

Transport is one of the main social determinants of health [1]. The way transport systems are designed, and the resources allocated to them, have the potential to disproportionately benefit or negatively impact certain population groups or neighbourhoods [2]. For example, original author(s) and the source, provide a link to the Creative Commons licence, and indicate if changes were made. The images or other third party material in this article are included in the article's Creative Commons licence, unless indicated otherwise in a credit line to the material. If material is not included in the article's Creative Commons licence and your intended use is not permitted by statutory regulation or exceeds the permitted use, you will need to obtain permission directly from the copyright holder. To view a copy of this licence, visit http://creativecommons.org/licenses/by/4.0/. The Creative Commons Public Domain Dedication waiver (http://creativeco mmons.org/publicdomain/zero/1.0/) applies to the data made available in this article, unless otherwise stated in a credit line to the data. 
building a transport system that prioritises private motor vehicles makes getting around more convenient - though less healthy and enjoyable [3] - for those people who can afford to own, and are able to drive, motor vehicles. Meanwhile the external effects of motor vehicle traffic, such as air and noise pollution, affect the health of disadvantaged groups more [4].

Giving more people the opportunity to ride a bicycle for everyday transport - through providing connected networks of quiet streets and paths protected from motor vehicle traffic - has well-documented public health, sustainability and economic benefits [5-7]. However, the health equity impacts of bicycle infrastructure projects or plans are rarely assessed. While there is a considerable literature on the equity of road pricing schemes and public transport, there is a smaller body of knowledge on the equity impacts of bicycle policies. The literature here includes studies on the use of bicycle share schemes by different population groups [8], but has largely failed to assess health aspects, including health equity [9].

The health benefits and costs measured in assessments of active transport interventions (e.g., new walking and cycling infrastructure) typically include changes in physical activity, road trauma and air pollution exposure $[5,10$, 11]. One example of a health equity-focused assessment of active transport infrastructure is that by Wu et al. [12], who developed a model to forecast changes in disability-adjusted life years attributable to changes in physical activity and road trauma, across race/ethnicity and income groups.

In Australia, cycling for transport is often viewed as the preserve of male, inner-city white-collar workers [13]. This view is supported by Census data, which show that bicycle commuters are most likely to have an aboveaverage income, be male, and be aged 20 to 49 years [14-16]. However, it is older adults and females who are more likely to be inactive or only moderately active (Australian Bureau of Statistics, 2019), and therefore have most to gain - physical activity-wise - from having more opportunities to cycle for everyday transport. Furthermore, the development of transport-oriented bicycle paths and networks (as opposed to recreational paths and trails) has been concentrated in gentrified, inner-city areas. Yet, it is outer-suburban residents who are less likely to be achieving sufficient physical activity to produce a health benefit [17].

Given the physical and mental health consequences of social/economic isolation and loneliness [18], and poor access to services (including health care) [19], another important benefit of bicycle infrastructure is improved accessibility, i.e., more opportunities to access jobs, education, social opportunities, services, healthy food options, etc. There are several established ways of measuring accessibility [20]. For example, contour measures simply count the number of opportunities that can be reached within a given travel time or distance of an origin. Utility-based measures are founded in welfare economics and attempt to place a monetary value on the range of destination and mobility choices available to an individual. Kent and Karner [21] used a contour measure to assess how accessibility to supermarkets, libraries and businesses would improve with a range of proposed bicycle infrastructure projects - and how these accessibility improvements would be distributed according to poverty status, race, and motor vehicle ownership status. We are aware of no equity-focused health assessment of an active transport intervention that has measured changes in accessibility using a utility-based measure.

\section{Methods \\ Aim}

In this study, we assess the health equity impacts of two planned bicycle infrastructure interventions in Sydney (Australia) - a single new cycleway, and a complete, connected network of cycleways. We define 'cycleway' as infrastructure comprising traffic-protected bicycle paths (also known as bicycle tracks) and/or shared pedestrian and bicycle paths (see Fig. 1).

\section{Setting}

The study area was the City of Sydney local government area (LGA), which is situated in the eastern part of the Greater Sydney metropolitan area in the Australian state of New South Wales (NSW). It comprises Sydney's main central business district (CBD) and the surrounding inner-city suburbs. It has a diverse population and has experienced significant gentrification in recent years, though pockets of socio-economic disadvantage remain.

Greater Sydney is car-oriented and not conducive to everyday transport cycling due to a lack of traffic-protected cycling facilities and a high default residential speed limit $(50 \mathrm{~km} / \mathrm{h})$ [22]. State laws also mandate the use of bicycle helmets, which can present a barrier to participation in transport cycling [23]. These laws are zealously enforced, with young Aboriginal and Torres Strait Islander peoples - who are less likely to have the means to pay the $\mathrm{A} \$ 344$ fine - targeted in particular [24, 25]. Despite these laws, cycling injury risk is relatively high for a high-income country [26, 27].

Some roads and streets have paint-marked bicycle lanes, but these are often situated in the hazardous 'door zone' between parked vehicles and general traffic lanes. At the time of data collection, the few existing cycleways were disconnected and lacked continuity, with very poor level of service (i.e., long waiting times) at signal-controlled intersections. The City of Sydney LGA is relatively 


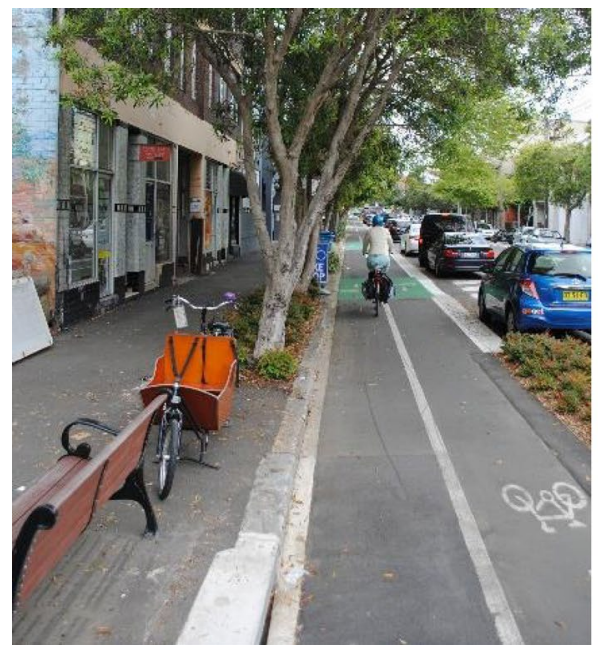

(a) Bicycle path

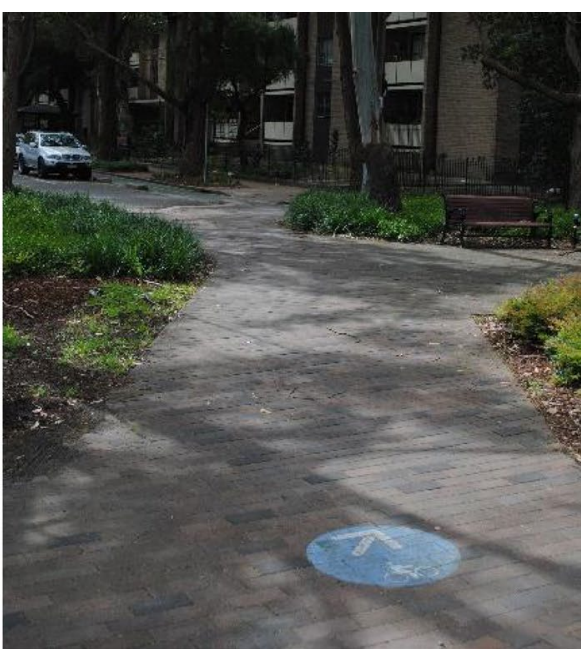

(b) Shared pedestrian and bicycle path

Fig. 1 Examples of cycleway infrastructure

hilly, which may partly explain the boom in e-bike sales in recent years [28]. The climate is temperate with hot, humid summers and mild winters, and an average of 144 rainy days and 1,211 $\mathrm{mm}$ of rain per year [29].

On the day of the 2016 Census, $4 \%$ of males and 1.8\% of females in the City of Sydney LGA commuted to work using a bicycle as their main transport mode. The respective values for Greater Sydney were 1.1 and 0.3\% [30].

As part of a policy to give more people the opportunity to use a bicycle for everyday transport, City of Sydney Council has a Cycle Strategy and Action Plan [31]. The centrepiece of this strategy is a planned $200 \mathrm{~km}$ bicycle network, including $55 \mathrm{~km}$ of cycleways.

\section{Approach}

Lee et al. [32] developed a theoretical framework for assessing the broad equity impacts of active transport policies and plans, which is summarised in Table 1 . The first step within this framework is to choose a model of distributive justice, i.e., whether resources should be targeted to address inequality, inequity or need [33]. The second step is to choose the equity lens(es), e.g., whether to assess the distribution of benefits and costs between different population groups or between geographic areas. The final step is to select the individual benefits and/or costs to measure.

Within this framework, we adopt the 'needs rule' with a 'social' equity lens - assessing how the health benefits of the two infrastructure intervention scenarios (relative to a Business as Usual scenario) are distributed across gender, age and income groups. The three scenarios are described in Table 2 and mapped in Fig. 2. The health benefits we measure are changes in physical activity and accessibility, which we forecast using a predictive transport mode choice model.

\section{Sample}

Data collection is described in detail elsewhere [34] but, for the benefit of the reader, a brief synopsis follows. Participants were recruited between September and November 2013. Eligibility was based on residential location (City of Sydney LGA only), age (18-55 years only) and self-reported ability to ride a bicycle. Recruitment was via several methods, including consumer panels, random digit dialling, letterbox drops, social media and electronic mailing lists.

Following recruitment, participants were asked to complete an online questionnaire and seven-day travel diary. Participants were given the option to download a smartphone tracking app to record their travel and assist them in completing their travel diaries. Those completing both the questionnaire and the travel diary were given a financial reward of $\$ A 65$.

\section{Variables}

In the questionnaire, participants were asked about their age, gender, household income, and education level. For the gender question, only two response options were available (female and male). 
Table 1 Theoretical framework for assessing equity in active transport planning - adapted from Lee et al. [32]

\begin{tabular}{|c|c|c|}
\hline \multirow[t]{3}{*}{ Models of distributive justice } & Equality rule & - Benefits and costs of active transport should be the same for everyone. \\
\hline & Equity rule & $\begin{array}{l}\text { - Benefits and costs of active transport should be distributed proportionally, } \\
\text { e.g., provide infrastructure where demand is highest. }\end{array}$ \\
\hline & Needs rule & $\begin{array}{l}\text {-The greatest benefit should be provided to the most disadvantaged popu- } \\
\text { lation groups or geographical areas. }\end{array}$ \\
\hline \multirow[t]{4}{*}{$\begin{array}{l}\text { Approaches to identifying inequities in measured } \\
\text { benefits or costs of active transport. }\end{array}$} & Social & $\begin{array}{l}\text { - Assesses how active transport benefits or costs are distributed between } \\
\text { different population groups. } \\
\text { - Focus is typically on disadvantaged population groups, e.g., low income, } \\
\text { indigenous, females. } \\
\text { - Disadvantaged population groups sometimes have the most to gain from } \\
\text { active transport policies, due to lower levels of physical activity, motor } \\
\text { vehicle ownership and access to public transport. }\end{array}$ \\
\hline & Spatial & $\begin{array}{l}\text { - Assesses how active transport benefits or costs are distributed between } \\
\text { different geographical areas (e.g., neighbourhoods). }\end{array}$ \\
\hline & Modal & $\begin{array}{l}\text { - Assesses whether users of a given mode of transport are better/worse off } \\
\text { than others, or disproportionately affected by a transport policy or project, } \\
\text { e.g., pedestrians having longer average waiting times at signal-controlled } \\
\text { intersections. }\end{array}$ \\
\hline & Procedural & $\begin{array}{l}\text { - Assesses the fairness of decision making, e.g., whether disadvantaged } \\
\text { groups/areas/modes are considered in, or disproportionately affected by, } \\
\text { strategies, plans, designs, etc. }\end{array}$ \\
\hline \multirow[t]{2}{*}{ Measures of the benefits and costs of active transport. } & Benefits & $\begin{array}{l}\text { - Availability or accessibility of active transport infrastructure. } \\
\text { - Accessibility to employment, education, public transport stops, supermar- } \\
\text { kets and other activity destinations. } \\
\text { - Active transport infrastructure quality, e.g., kerb ramps and pavement } \\
\text { quality. } \\
\text { - Physical activity associated with active transport. }\end{array}$ \\
\hline & Costs & $\begin{array}{l}\text { - Exposure to air pollution. } \\
\text { - Risk of being killed/injured by a motor vehicle driver. }\end{array}$ \\
\hline
\end{tabular}

Table 2 Scenario descriptions

\begin{tabular}{ll}
\hline Scenario & Description \\
\hline Business as Usual & The bicycle network as it existed in 2013. \\
Single Cycleway & $\begin{array}{l}\text { The } 2013 \text { network, plus a single } 2.4 \mathrm{~km} \text { cycleway along George Street, connecting the Green Square urban } \\
\text { renewal area in Sydney's Inner South with the CBD, and passing through suburbs with a large amount of public } \\
\text { housing and Aboriginal Housing Office housing (Waterloo and Redfern). }\end{array}$ \\
Complete Network & The 2013 network, plus completion of the bicycle network proposed in the Cycle Strategy and Action Plan [31].
\end{tabular}

Physical activity in the previous week was measured using the Active Australia Survey [35]. Participants were also asked what type of bicycle rider they most identified as [36]. Response options were:

a) 'A low-intensity recreational bike rider - you like the fresh air and exercise, and cycle at an enjoyable pace';

b) 'A high-intensity recreational bike rider - you like to ride hard and fast';

c) 'A low-intensity transport bike rider - you are about just getting to places, and you travel at a more comfortable speed'; and d) 'A high-intensity transport bike rider - you are a fast rider who likes to keep up a fast pace throughout your journey'.

For analysis and presentation purposes, this variable was dichotomised as 'high intensity' and 'low intensity'.

The seven-day travel diary collected, for each activity of each day: activity type (e.g., 'commute to work/study' or 'shopping'), mode of transport, access and egress modes of transport (for public transport trips), origin, destination, departure time and arrival time [37].

Daily rainfall data were obtained from the Bureau of Meteorology [38]. 

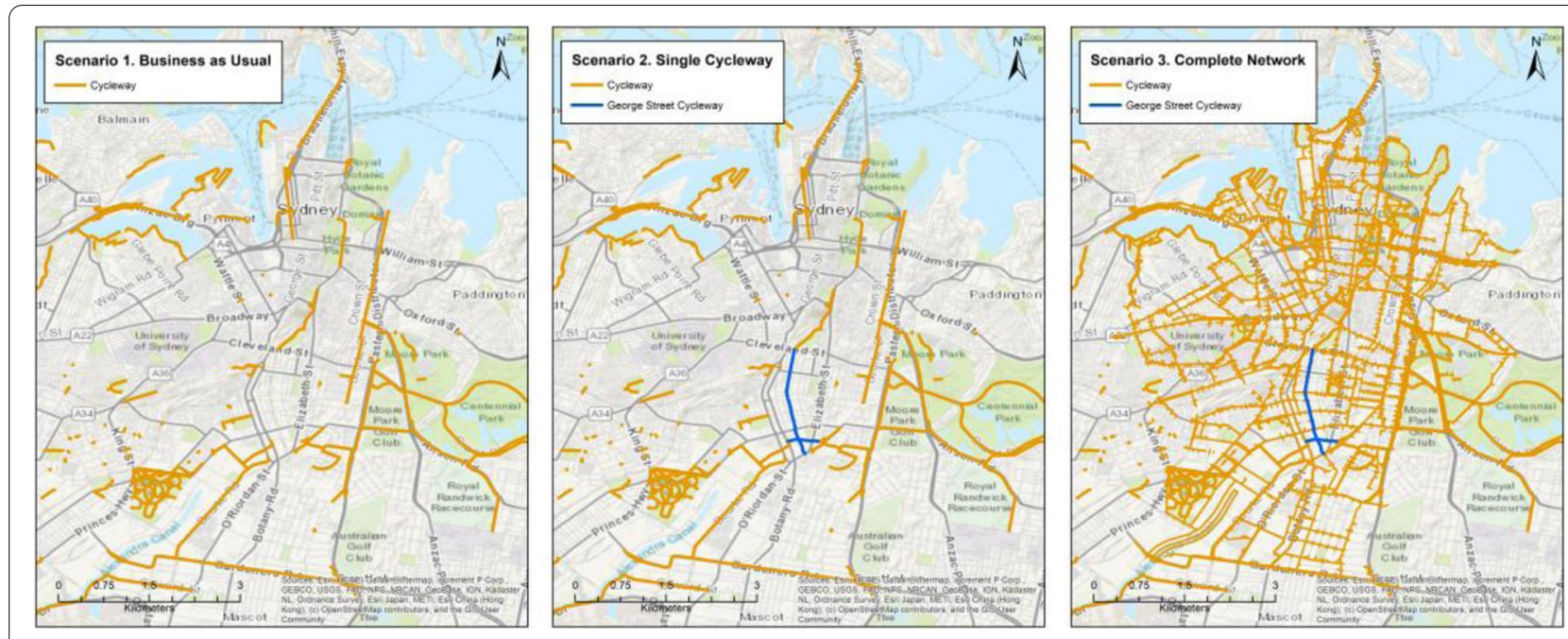

Fig. 2 Scenario maps

\section{Analysis}

Analysis comprised three main steps: (1) using the collected data to train a predictive transport mode choice model; (2) using this model to forecast the impact of the two intervention scenarios on transport mode choice, physical activity and accessibility; and (3) assessing how the forecast physical activity and accessibility changes are distributed across gender, age and income groups. More detail on each step is provided below.

\section{Predictive transport mode choice model}

For each trip reported in the travel diary, the travel time/ distance attributes (i.e., features or independent variables) of four transport mode alternatives (walk, bicycle, public transport and car) were imputed from the reported origin and destination, using ArcGIS Network Analyst software [39] and the Google Directions application programming interface [40].

Mode choice (the label/dependent variable) was coded as the reported transport mode for the trip - or, for multimodal trips, the mode with the highest priority in the hierarchy used by the NSW Bureau of Transport Statistics [41].

For each choice situation (i.e., trip) $t$, it was assumed that the observed utility $V_{n j t}$ (i.e., the relative attractiveness) of transport mode alternative $j$ to individual $n$ is given by:

$$
V_{n j t}=\alpha_{j}+\beta_{n}^{\prime} x_{n j t}, t=1, \ldots, T_{i},
$$

where: $x_{n j t}$ is a vector of individual characteristics (e.g., age), trip attributes (e.g., cycleway distance), contextual factors (e.g., daily rainfall below/above $3 \mathrm{~mm}$ ) and interaction terms (e.g., non-cycleway distance multiplied by high/low-intensity bicycle rider); $\beta^{\prime}$ is a vector of parameters to be estimated; and $\alpha_{j}$ are alternative-specific constants.

The mixed logit model was chosen because it can account for panel data, i.e., correlation between multiple choice situations (trips) for one individual. Separate models were estimated for commuting and non-commuting trips. The alternative-specific constant for the walk alternative was normalised to zero. For the random parameters, it was found that a triangular distribution with spread constrained to be half the mean - gave the best behavioural interpretation. Models were estimated by simulated maximum likelihood using NLOGIT version 6 choice modelling software [42].

The modelled attributes of bicycle utility included distance, which was broken down into cycleway distance and non-cycleway distance. Thus, if the parameter estimate for non-cycleway distance is more negative than that for cycleway distance, then interventions that allow more of a trip to be undertaken on cycleways will increase the utility of cycling, and the probability $P_{n t}$ of bicycle being chosen for that trip:

$$
P_{n t, j=b i c y c l e}=\frac{\exp \left(V_{n t, j=b i c y c l e}\right)}{\exp \left(V_{n t, j=w a l k}\right)+\exp \left(V_{n t, j=b i c y c l e}\right)+\exp \left(V_{n t, j=\text { public transport }}\right)+\exp \left(V_{n t, j=c a r}\right)} .
$$

The bicycle utility function also included as trip attributes: dummy variables for daily rainfall greater than $3 \mathrm{~mm}$ (Rain $>3 \mathrm{~mm}$ (Bicycle)), and whether the trip began or ended in the CBD (CBD (Bicycle)). The car utility function included as trip attributes: travel time, and a dummy variable indicating whether the trip began or ended in the CBD (CBD (Car)). Only 
travel time was retained as a trip attribute in the walk and public transport utility functions. Non-statistically significant variables were omitted from the final models.

\section{Forecasting}

For all three scenarios, it was assumed that each participant would make the same trips they reported in their seven-day travel diary, with the same origins and destinations, and that the attributes for the walk, public transport and car alternatives would not change. For the bicycle alternative, the imputed cycleway and noncycleway distances could differ in each scenario, due to the addition of new cycleways to the network.

For each trip in each scenario, the expected values of walking time and cycling time were calculated using a simulation model developed using Microsoft Excel [43] - with the probability of a transport mode being chosen calculated using Eq. (2) and daily rainfall simulated at random based on the historical rainfall data. Cycling time was derived from cycling distance, assuming an average cycling speed of $15 \mathrm{~km} / \mathrm{h}$ (the value used by the United Kingdom Department of Transport for adults with limited cycling experience [44]). Differences in annual walking time and annual cycling time between each intervention scenario and Business as Usual were calculated and multiplied by 52.1 to obtain annual forecasts.

Following Train [45], de Jong et al. [46] and Geurs and van Wee [20], differences in utility-based accessibility $A_{n t}$ between an intervention scenario $(s=2)$ and Business as Usual $(s=1)$ were calculated as:

$$
\Delta E\left(A_{n t}\right)=\left(1 / \alpha_{n}\right) \ln \left(\sum_{j} \mathrm{e}^{\mathrm{V}_{\mathrm{ntj}}^{\mathrm{s=2}}}\right)-\left(\sum_{j} \mathrm{e}^{\mathrm{V} \mathrm{V}_{\mathrm{nt}}^{\mathrm{s}=1}}\right) .
$$

The marginal utility of income $\alpha_{n}$ is, by definition, the negative of the parameter of any monetary variable in a mode choice model, e.g., public transport fare [45]. Because there was no monetary variable in our model, a variable with a well-established monetary valuation was chosen; namely, the value of travel time savings, which the NSW Government valued at an average of \$A15.14/ hour [47].

\section{Equity analysis}

The resulting outcome variables of annual walking time (hours), annual cycling time (hours) and utility-based accessibility changes (A\$) were aggregated by participant and averaged for each gender, age and income group (as listed in Table 3). Forecast changes in physical activity for each population group were compared across the two intervention scenarios using slope graphs. Forecast increases in cycling time and utility-based accessibility per person per year per kilometre of new cycleway were compared across population groups for each intervention scenario using grouped bar charts. This analysis was performed using Microsoft Excel [43] and Tableau Desktop [48].

\section{Results}

Descriptive data

Table 3 shows the characteristics of the 267 participants. The high proportion of female and older participants is not an issue for equity analyses, because changes in

Table 3 Sample characteristics

\begin{tabular}{|c|c|c|c|c|c|}
\hline & $\mathrm{n}$ & $\begin{array}{l}\text { Average self-reported minutes } \\
\text { of physical activity per week }\end{array}$ & $\begin{array}{l}\% \text { that are } \\
\text { sufficiently } \\
\text { physically active }\end{array}$ & $\begin{array}{l}\text { Average (self-reported) } \\
\text { body mass index (BMI) }^{\text {a }}\end{array}$ & $\begin{array}{l}\text { Average number of } \\
\text { reported trips (seven } \\
\text { days) }\end{array}$ \\
\hline \multicolumn{6}{|l|}{ Gender } \\
\hline Female & $212(79 \%)$ & 557 & 95 & 20.9 & 18.7 \\
\hline Male & $55(21 \%)$ & 533 & 82 & 26.3 & 17.7 \\
\hline \multicolumn{6}{|l|}{ Age (years) } \\
\hline $18-29$ & $78(29 \%)$ & 598 & 95 & 19.1 & 17.7 \\
\hline $30-44$ & $56(21 \%)$ & 577 & 84 & 24.8 & 18.9 \\
\hline $45-55$ & $133(50 \%)$ & 515 & 95 & 22.3 & 18.8 \\
\hline \multicolumn{6}{|c|}{ Household income (\$A) } \\
\hline$<80,000$ & $101(38 \%)$ & 467 & 93 & 22.1 & 17.7 \\
\hline$>=80,000$ & $103(39 \%)$ & 755 & 93 & 24.3 & 18.9 \\
\hline Prefer not to say & $63(24 \%)$ & & & & \\
\hline
\end{tabular}

${ }^{\text {a }}$ For most people, a BMI of 18.5 to 24.9 is within the healthy weight category 
outcome measures are averaged for each population group. Only 204 participants reported their income, so analyses involving income are limited to this subsample. The majority of participants reported at least $150 \mathrm{~min}$ of moderate to vigorous activity, which the Department of Health [49] considers to be sufficient weekly physical activity for adults aged 18-64. Of the 267 participants, 229 reported at least one commuting trip and 259 reported at least one non-commuting trip. Between them, they reported 4,936 trips.

\section{Predictive transport mode choice model results}

The final transport mode choice models for commuting and non-commuting are presented in Table 4. The models are a significant improvement over constants only ones $(p<0.01)$ and fit the data well (pseudo- $R^{2} \geq 0.56$ ).

The two bicycle distance parameters have the expected negative sign. As expected, cycleway distance is preferred over non-cycleway distance, and the difference between them is statistically significant in both models ( $t$-statistic $\geq 2.36$ ). The marginal rates of substitution ( $\beta_{\text {Non-cycleway }}$ distance $/ \beta_{\text {Cycleway distance }}$ ) indicate that people will take a longer, less direct route to ride on cycleways instead of amongst traffic. On average, they will opt to ride for up to $1.4 \mathrm{~km}$ (commuting) or up to $1.6 \mathrm{~km}$ (not commuting) on cycleways, rather than ride for $1 \mathrm{~km}$ on facilities not protected from traffic.

Self-reported bicycle rider type has a significant influence on sensitivity to non-cycleway distance (i.e., aversion to cycling in traffic), with respondents identifying as 'low intensity' having a higher sensitivity.

The parameters for household income, education level, gender and age are not statistically significant; therefore, these variables are omitted in the final models.

\section{Physical activity forecasts}

Figures 3, 4, 5 and 6 show the forecast hours of physical activity per person per year for the two intervention scenarios, relative to Business as Usual. In the Single Cycleway scenario, average cycling hours per person per year are forecast to increase by $18.9 \%$. The forecast increase for males $(19.0 \%)$ is almost identical to that for females $(18.9 \%)$ and marginally greater for the highincome group (20.2\% versus $18.6 \%$ ) and the $45-55$ age group (21.8\% versus $17.8 \%$ for the $18-29$ age group and $16.9 \%$ for the $30-44$ age group).

Table 4 Mixed logit models of transport mode choice

\begin{tabular}{|c|c|c|c|c|c|c|}
\hline & \multicolumn{3}{|c|}{ Commuting (1,788 trips) } & \multicolumn{3}{|c|}{ Non-commuting $(3,148$ trips $)$} \\
\hline & $\beta$ & $\begin{array}{l}95 \% \\
\text { confidence } \\
\text { interval }\end{array}$ & t-statistic & $\beta$ & $\begin{array}{l}95 \% \\
\text { confidence } \\
\text { interval }\end{array}$ & t-statistic \\
\hline \multicolumn{7}{|l|}{ Alternative-specific constants } \\
\hline Bicycle & -4.92 & -5.62 to -4.21 & -13.66 & -2.77 & -2.99 to -2.55 & -24.86 \\
\hline Public transport & -4.70 & -5.55 to -3.85 & -10.83 & -5.59 & -6.02 to -5.16 & -25.25 \\
\hline Car & -2.79 & -3.41 to -2.16 & -8.76 & -2.61 & -2.81 to -2.41 & -25.96 \\
\hline \multicolumn{7}{|c|}{ Random parameters (specific alternative) ${ }^{a}$} \\
\hline Cycleway distance (Bicycle) & -1.89 & -2.16 to -1.6 & -13.15 & -2.07 & -2.35 to -1.78 & -14.24 \\
\hline Non-cycleway distance (Bicycle) & -2.65 & -3 to -2.3 & -15.05 & -3.35 & -3.84 to -2.86 & -13.37 \\
\hline CBD (Bicycle) & -1.52 & -2.06 to -0.98 & -5.52 & -2.31 & -3.18 to -1.44 & -5.19 \\
\hline Time (Walk) & -0.41 & -0.45 to -0.37 & -22.88 & -0.37 & -0.39 to -0.36 & -49.39 \\
\hline Time (Public transport) & -0.44 & -0.46 to -0.41 & -40.26 & -0.32 & -0.34 to -0.29 & -25.02 \\
\hline Time (Car) & -1.17 & -1.23 to -1.10 & -36.13 & -0.76 & -0.79 to -0.73 & -47.47 \\
\hline CBD (Car) & -5.66 & -6.18 to -5.13 & -21.07 & -3.71 & -4.21 to -3.2 & -14.39 \\
\hline \multicolumn{7}{|c|}{ Non-random parameters (specific alternative) } \\
\hline $\begin{array}{l}\text { Non-cycleway distance x Low } \\
\text { intensity (Bicycle) }\end{array}$ & -1.16 & -1.38 to -0.92 & -9.68 & -0.99 & -1.25 to -0.74 & -7.76 \\
\hline Rain > 3 mm (Bicycle) & & & & -0.79 & -1.16 to -0.43 & -4.26 \\
\hline \multicolumn{7}{|l|}{ Model fit statistics } \\
\hline Log likelihood & -2478.7 & & & -1928.8 & & \\
\hline Chi-square & $2887.5(p<0.01)$ & & & $4878.7(p<0.01)$ & & \\
\hline Degrees of freedom & 11 & & & 12 & & \\
\hline Pseudo- $R^{2}$ & 0.58 & & & 0.56 & & \\
\hline Akaike information criterion & 2091.9 & & & 3881.6 & & \\
\hline
\end{tabular}

${ }^{a}$ All random parameters have a triangular distribution with spread equal to half the mean 


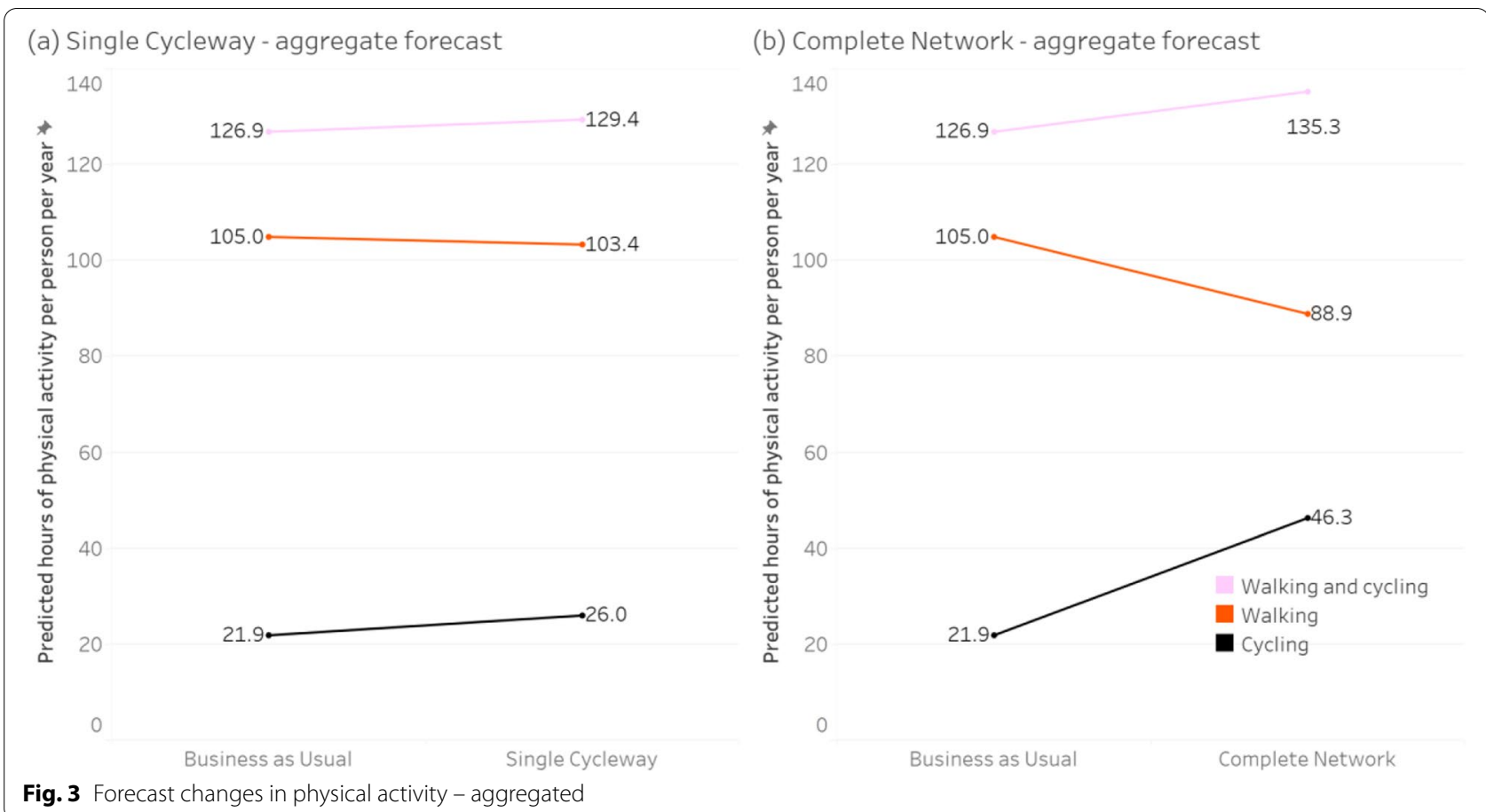

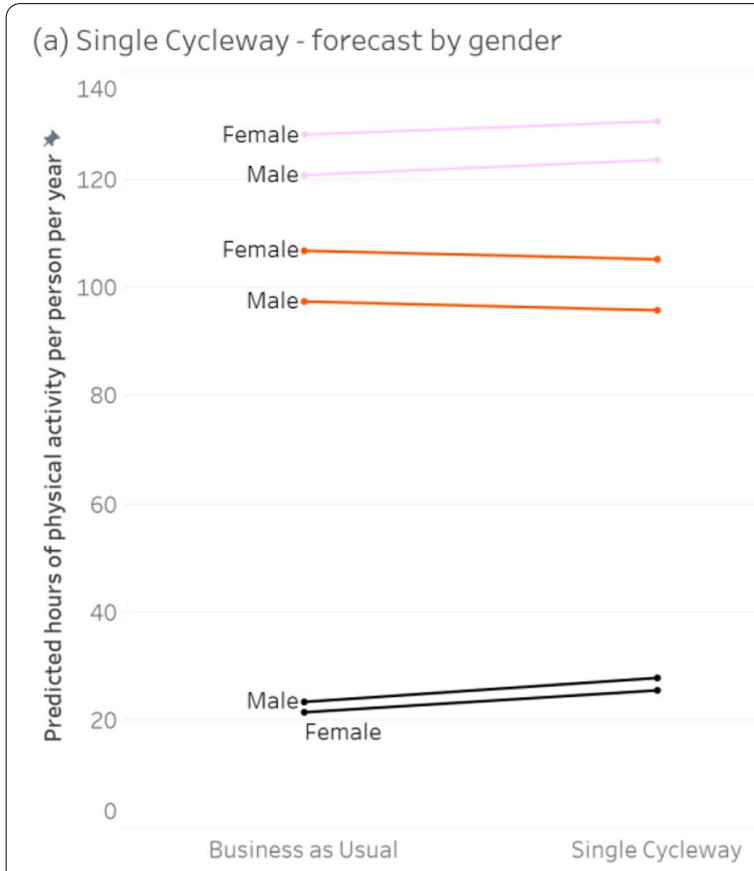

Fig. 4 Forecast changes in physical activity - grouped by gender (b) Complete Network - forecast by gender

140

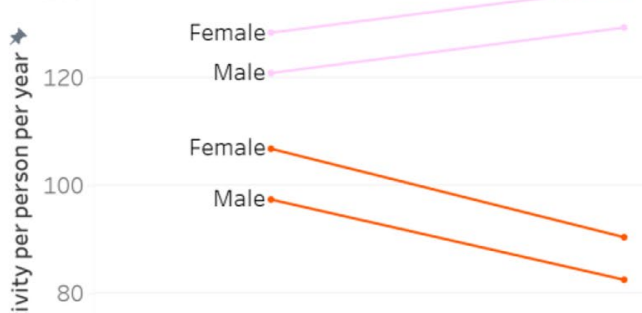

80

60

40

20

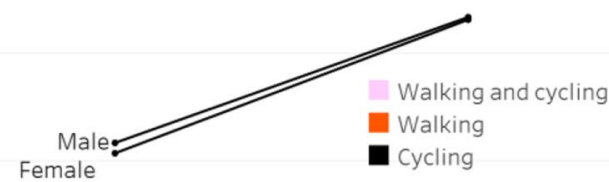

0

Business as Usual

Complete Network
In the Complete Network scenario, average cycling hours are forecast to more than double (111.7\% increase). As with the Single Cycleway scenario, the forecast increase is greatest for the $45-55$ age group
(119.1\%). However, in this scenario, the forecast increase is greater for females than males (115.1 versus 99.5\%) and greater for the low-income group than the high-income group (117.2 versus $112.0 \%$ ). 


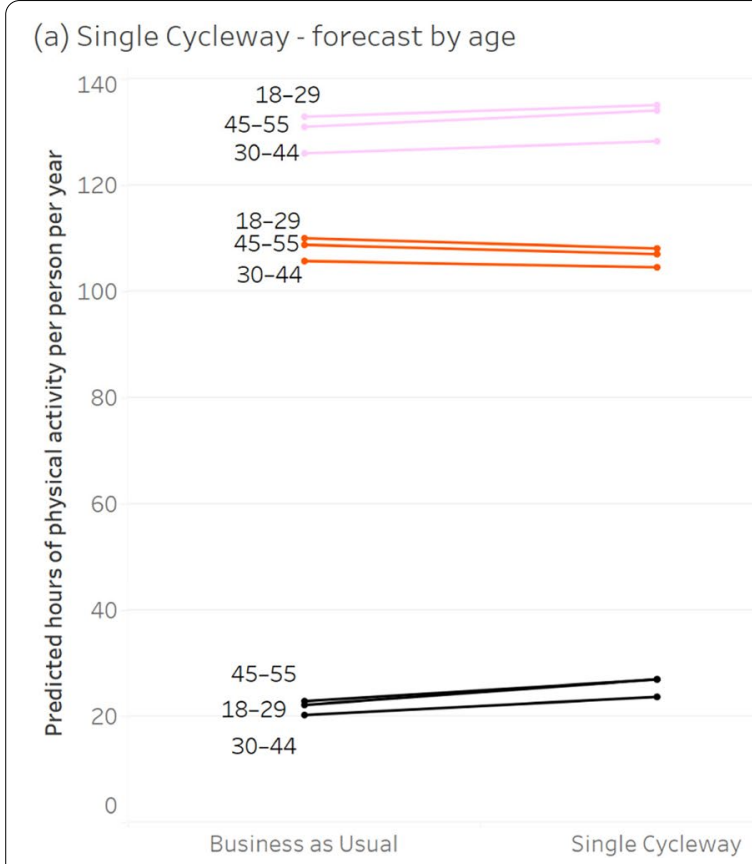

(b) Complete Network - forecast by age

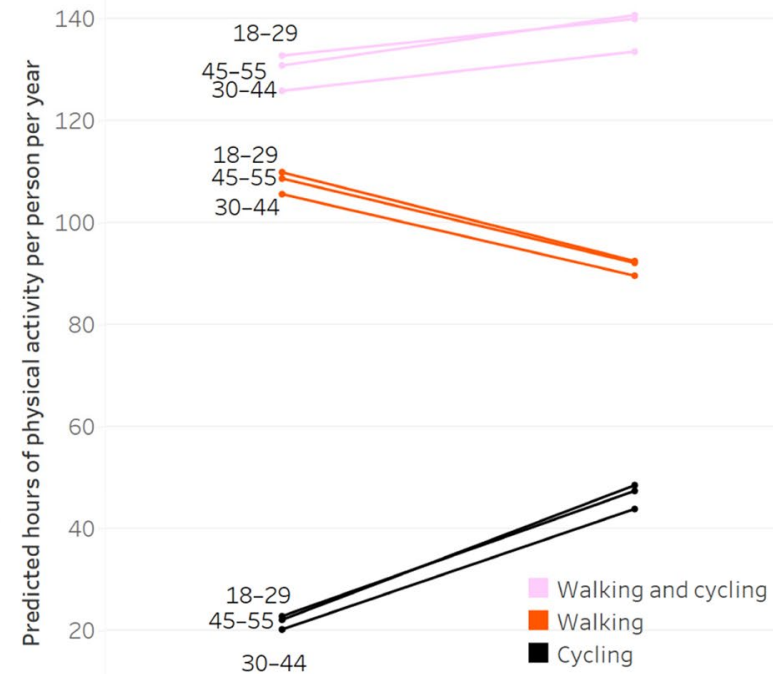

Fig. 5 Forecast changes in physical activity - grouped by age

(a) Single Cycleway - forecast by income

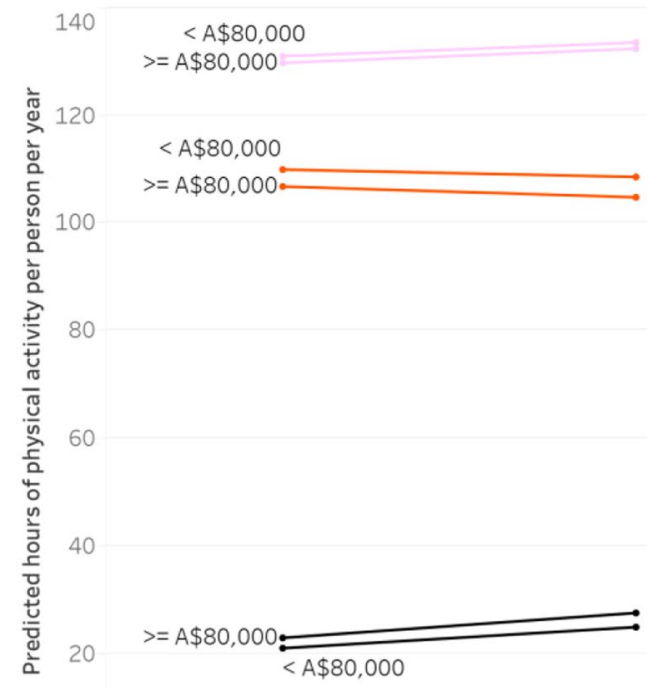

0

Fig. 6 Forecast changes in physical activity - grouped by income

(b) Complete Network - forecast by income

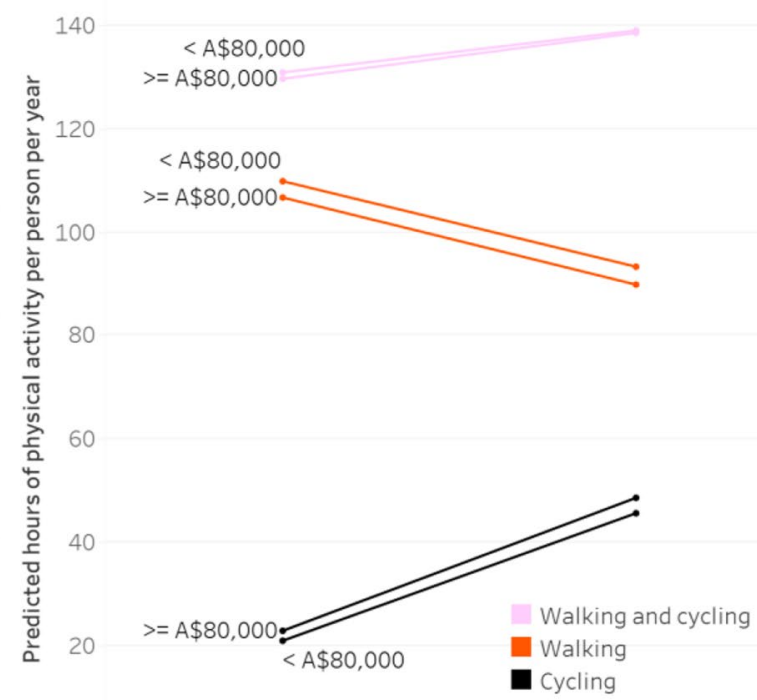

Business as Usual 
Network scenario could be due to respondents in this group being more likely to identify as low-intensity bicycle riders $\left(\mathrm{X}^{2}=10.5, p=0.001\right)$ and having a greater aversion to riding amongst traffic.

In both intervention scenarios, increases in cycling time for all groups are partially offset by forecast decreases in walking time - which can be attributed to (a) some of the new cycling trips having previously been made by walking, and (b) those new cycling trips having a shorter travel time than the walking trips they replace, owing to the higher speed of bicycle (assuming destination choice is independent of transport mode choice).

However, in both intervention scenarios, there is still an increase in combined walking and cycling time: $2.0 \%$ in the Single Cycleway scenario and 6.6\% in the Complete Network scenario, albeit with little difference between gender, age and income groups.

Figure 7 shows the forecast increase in cycling physical activity per person per year for each kilometre of new cycleway built. In the Single Cycleway Scenario, each new kilometre of cycleway is forecast to result in greater increases in cycling physical activity among males than among females, among the 18-29 and 45-55 age groups, and among the high-income group. In the Complete Network scenario, forecast increases in cycling physical activity are roughly equal for all groups. While the Complete Network scenario is forecast to have a greater overall cycling physical activity benefit than the Single Cycleway scenario, the benefit per new cycleway kilometre is less, indicating diminishing returns as the network grows.

\section{Accessibility forecasts}

Figure 8 shows the forecast value of accessibility improvements per person per year for each kilometre of new cycleway built. Overall, the Complete Network scenario has a $76 \%$ greater accessibility benefit per cycleway kilometre than the Single Cycleway scenario.

With the Single Cycleway, the accessibility benefit per cycleway kilometre is $37 \%$ greater for males than females, and $50 \%$ greater for the high-income group than the lowincome group. These differences reduce to 5 and $11 \%$ respectively in the Complete Network scenario.

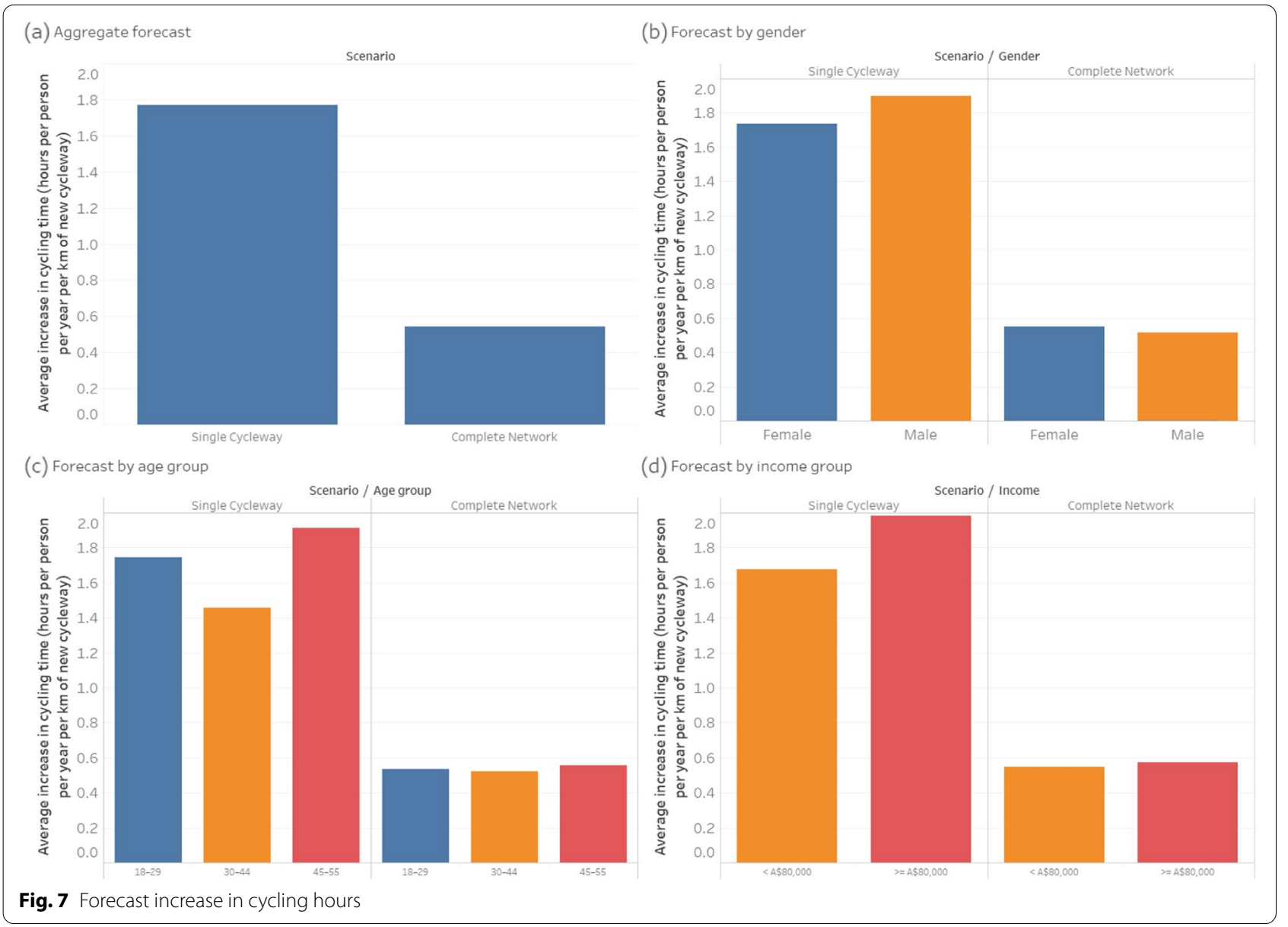



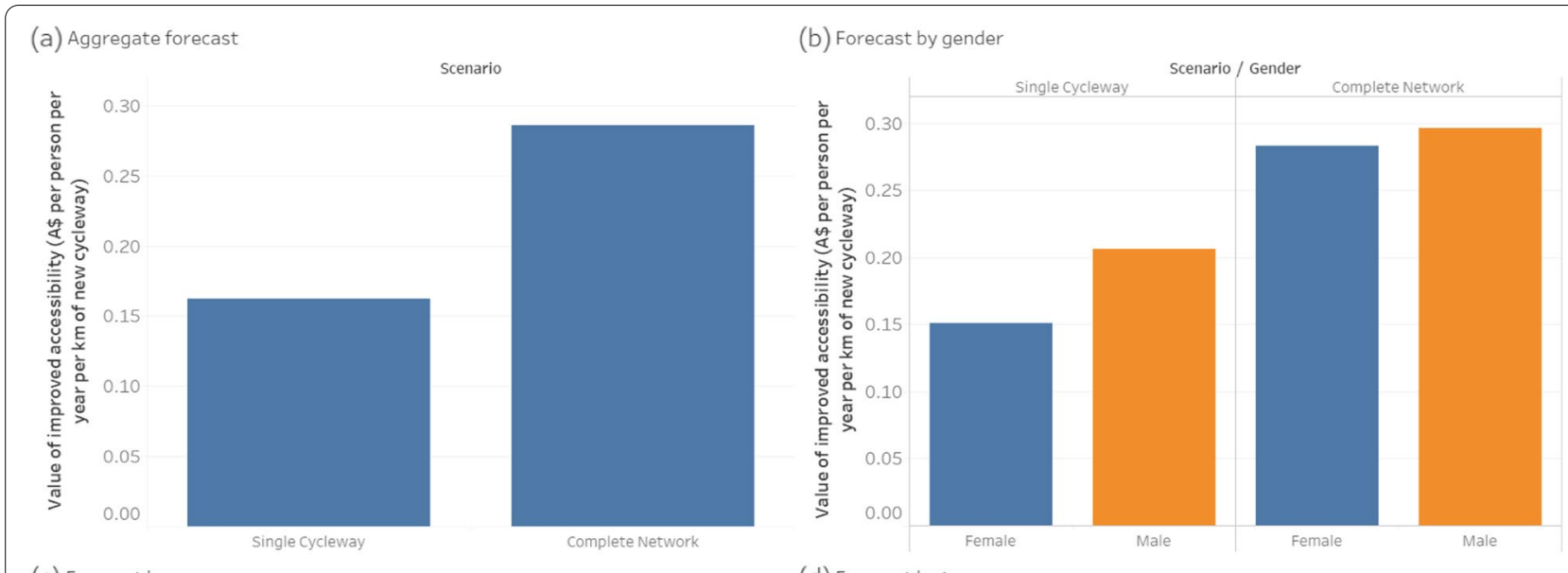

(c) Forecast by age group

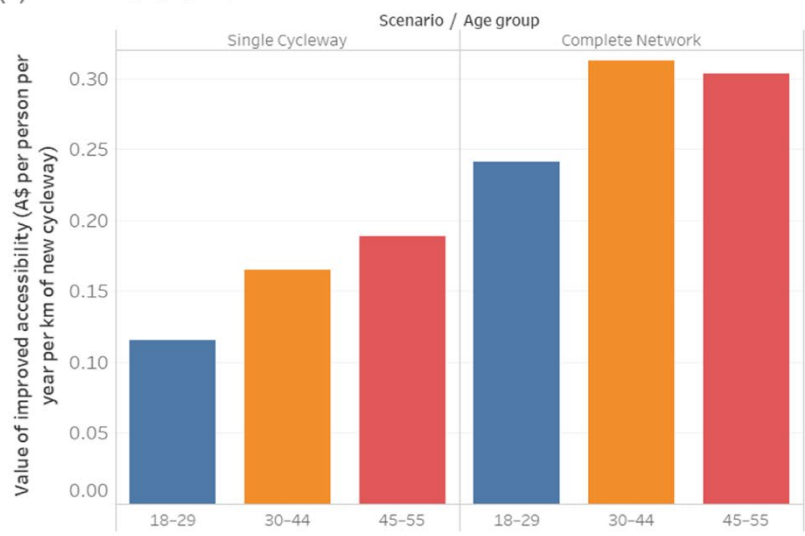

(d) Forecast by income group

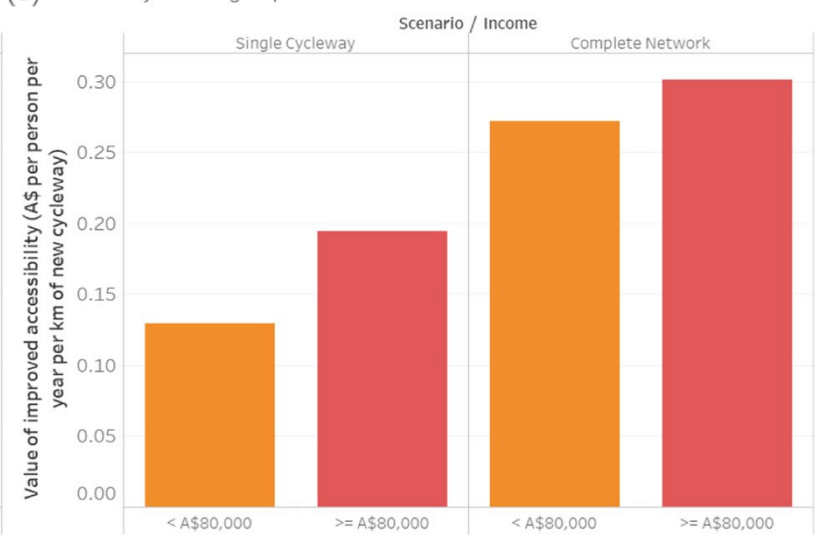

Fig. 8 Forecast value of improved accessibility

\section{Discussion}

This study explored the potential impacts of new bicycle infrastructure on physical activity and accessibility across gender, age and income groups - for both a smallscale intervention (Single Cycleway) and a large-scale one (Complete Network).

The results suggest that: (a) the overall physical activity and accessibility benefits of new cycleways increase when they are joined into a fully-connected network that allows end-to-end, traffic-free cycling between multiple origins and destinations; (b) the accessibility benefits are amplified (due to network effects), but with a diminishing return in the physical activity benefits; and (c) the physical activity and accessibility benefits of new cycleways are much more equally distributed across population groups when they are joined into a complete network.

The forecasts are consistent with cycling participation data from other high-income countries, which show that, in cities with sparse/disconnected cycling infrastructure, transport cycling is predominantly an option for young and middle-aged adult males. Conversely, in cities with connected, low-stress bicycle networks, people of all genders and ages cycle for everyday transport [50-53].

The predictive transport mode choice model developed for this study reflects previous studies indicating that people prefer cycling on protected cycleways over cycling in traffic, and will take a less direct/more timeconsuming route to do so [54-56]. That people willingly choose a longer route for greater journey utility raises questions about the implied objectives of speed increases and 'travel time savings' in much traffic engineering and transport planning practice and research [57].

Using our model to forecast the physical activity benefits of two bicycle infrastructure intervention scenarios, we estimate the Single Cycleway would increase average weekly cycling time per person from 25 to $30 \mathrm{~min}$, while the Complete Network would more than double it, to $53 \mathrm{~min}$. In both scenarios, some walking trips would be replaced by cycling trips (of similar distance and therefore reduced duration), resulting in a reduction in walking time. However, there is still a net increase in average weekly walking and cycling time, from 146 to $149 \mathrm{~min}$ 
in the Single Cycleway scenario, and to $156 \mathrm{~min}$ in the Complete Network scenario. In practice, a person switching from walking to cycling may opt for a more distant destination, because the higher speed of bicycle means they can access it in a similar time [58]. Accordingly, these forecast physical activity increases are likely to be conservative.

For reference, Australia's Department of Health recommends a minimum of 150 min of moderateintensity physical activity per week [59], which is in accordance with World Health Organization guidelines [60]. While (non-brisk) walking is not considered in the guidelines to be a moderate-intensity activity, cycling is. Thus, in the Complete Network scenario, the proportion of the recommended $150 \mathrm{~min}$ that could be achieved through transport cycling alone would increase from 17 to $35 \%$.

Females and older adults in Australia are more likely to be inactive or only moderately active [61], which increases their risk of heart disease, type II diabetes and some cancers [62]. As such, the finding that, in the Complete Network scenario, greater physical activity benefit accrues to females and the 45-55 age group is encouraging from a health equity perspective. However, it should be noted that, in our sample, $95 \%$ of females were already sufficiently physically active to begin with.

The greater accessibility benefit forecast for the highincome group and the older age group can be partly explained by the greater number of trips reported by these groups (see Table 3), and we have assumed that the number of trips each person makes would be the same in all scenarios. In practice, new bicycle infrastructure may enable people in the other groups to make more trips.

The disaggregate transport demand forecasting model used for this study (in which forecasts are made for individuals with linked sociodemographic characteristics) enables greater insight into health equity outcomes than would be possible using the type of aggregate demand model typically used by transport authorities [46]. Our model also uses a finer spatial resolution than typical aggregate demand models (in which trip origins and destinations are approximated to zone centroids), allowing improved modelling of short-distance walking and cycling trips. However, like all predictive models, it involves many assumptions and several limitations. We have assumed that changes in a person's cycling physical activity resulting from an infrastructure intervention may affect only their walking physical activity. However, it is also possible that a person spending more time cycling may replace other types of physical activity, e.g., working out at a gym. A systematic review of studies of the impact of built environment changes on physical activity and active transport [63] found largely positive effects for cycling physical activity, but was inconclusive in relation to overall physical activity.

We have also assumed that only transport mode choice and bicycle route choice would be affected by a bicycle infrastructure intervention. However, it is also likely that home location, work location, number of trips, departure time and destination choices would also be affected. For example, a person switching from driving to cycling for grocery shopping may opt for more frequent trips to a closer supermarket without car parking. Likewise, a person financially constrained from using public transport may make more trips and visit more distant destinations, given the option to get around by bicycle.

Achieving recruitment quotas for some population groups proved challenging, resulting in a convenience sample not representative of the population on certain demographics. While changes in outcome measures were averaged for each population group, the under-representation of some population groups may have biased the calculations. Furthermore, more people with a predisposition to healthy and active living may have self-selected for a survey about transport and health.

The forecast benefits are likely to be conservative because they do not include those accruing to people living outside the City of Sydney LGA, nor people aged less than 18 or more than 55 years. Nor do they include potential benefits associated with increased recreational cycling or improved opportunities to access or egress public transport (i.e., to get from a trip origin, e.g., home, to a public transport stop, or to get from a public transport stop to a destination, e.g., work).

Data were collected before the introduction of dockless bicycle share and widespread e-bike adoption in Sydney. While riding an e-bike is still a form of physical activity, it is generally lower intensity than riding a conventional bicycle; however, e-bike use is associated with more overall minutes of physical activity because users cycle more frequently and further than they would otherwise [64]. Future transport demand models used to predict impacts of bicycle infrastructure could include e-bike as a distinct transport mode alternative, or as an attribute in the bicycle alternative.

Despite the limitations and conservative estimates of this study, we have demonstrated how the distributions of physical activity and accessibility benefits of bicycle infrastructure can be assessed. While the findings are specific to inner-city Sydney, where most everyday destinations are within cycling distance, the method could be used anywhere that disaggregate transport demand data linked with personal characteristics are available.

The study indicates that bicycle infrastructure projects are likely to improve physical activity and accessibility for some population groups more than others, but that the benefits may be more evenly distributed with a fully 
connected, low-stress bicycle network. Thus, it could be argued that failure to provide a connected, low-stress bicycle network is an example of structural discrimination [65], as doing so limits the physical activity and independent access opportunities of females and other population groups most averse to cycling in traffic.

As such, we suggest that planning and assessment of major bicycle projects in future should consider the distributions of key benefits (and costs), especially (a) how much physical activity benefit accrues to population groups with higher incidence of inadequate physical activity (these being females and older adults in Australia); and (b) to what extent they could narrow existing disparities between population groups in opportunities to access economic/social opportunities and services.

\section{Conclusions}

In a traffic-dominated city such as Sydney, certain population groups, notably females, have less opportunity to access everyday destinations by bicycle - and, therefore, incorporate moderate/high-intensity physical activity into their daily schedules - because of their greater aversion to riding in traffic. This inequity can be addressed with connected bicycle networks that provide more opportunities for people of all genders, ages and incomes to cycle to multiple destinations in a traffic-free environment.

\section{Abbreviations}

BMI: Body mass index; CBD: Central business district; LGA: Local government area; NSW: New South Wales.

\section{Acknowledgements}

We would like to thank members of the study advisory committee: Michelle Daley, Ben Cebuliak, Fiona Campbell, Lyndall Johnson, Peter McCue and Rema Hayek.

\section{Authors' contributions}

Chris Rissel, Stephen Greaves, Melanie Crane and Christopher Standen contributed to the study design and data collection. Andrew Collins advised on the predictive transport mode choice modelling methodology and results interpretation. Christopher Standen performed all analyses and drafted the manuscript. All other authors contributed to the manuscript. The author(s) read and approved the final manuscript.

\section{Funding}

Data collection was supported by the Australian Research Council (grant number LP120200237).

\section{Availability of data and materials}

The datasets used and/or analysed during the current study are available from the corresponding author on reasonable request.

\section{Declarations}

Ethics approval and consent to participate

All procedures were performed in compliance with relevant laws and institutional guidelines Ethics approval for the study was granted by the University of Sydney's Human Research Ethics Committee (Project No. 2012/2411). Informed consent was obtained for experimentation with human participants.

\section{Consent for publication}

Not applicable.

\section{Competing interests}

The authors declare that they have no competing interests.

\section{Author details}

${ }^{1}$ Centre for Primary Health Care and Equity, School of Population Health, University of New South Wales, Kensington, NSW 2052, Australia. ${ }^{2}$ Health Equity Research and Development Unit, Sydney Local Health District, Missenden Road, PO Box M30, Camperdown, NSW 2050, Australia. ${ }^{3}$ Sydney School of Public Health, Charles Perkins Centre, The University of Sydney, Camperdown, NSW 2006, Australia. ${ }^{4}$ Institute of Transport and Logistics Studies, The University of Sydney Business School, The University of Sydney, Darlington, NSW 2006, Australia.

Received: 24 May 2021 Accepted: 31 August 2021

Published online: 15 September 2021

References

1. Marmot M. Social determinants of health inequalities. Lancet. 2005:365:1099-104

2. Litman T. Evaluating transportation equity: guidance for iincorporating distributional impacts in transportation planning. Victoria; 2021. Available from: https://www.vtpi.org/equity.pdf

3. Rissel C, Crane M, Wen LMLM, Greaves S, Standen C. Satisfaction with transport and enjoyment of the commute by commuting mode in inner Sydney. Heal Promot J Aust. 2015;27:80-3. CSIRO.

4. Feitelson E. Introducing environmental equity dimensions into the sustainable transport discourse: Issues and pitfalls. Transp Res Part D Transp Environ. 2002;7:99-118.

5. Mueller N, Rojas-Rueda D, Cole-Hunter T, de Nazelle A, Dons E, Gerike R, et al. Health impact assessment of active transportation: a systematic review. Prev Med (Baltim). 2015;76:103-14. Elsevier Inc.

6. Rabl A, de Nazelle A. Benefits of shift from car to active transport. Transp Policy. 2012;19:121-31. Elsevier.

7. Garrard J, Rissel C, Bauman A, Giles-Corti B. Cycling and health. In: Buehler R, Pucher J, editors. Cycl Sustain Cities. Cambridge: MIT Press; 2021. p. 35-56.

8. Fishman E, Washington S, Haworth N. Bike share: a synthesis of the literature. Transp Rev. 2013;33:148-65. Available from: https://www.scopus. com/inward/record.url?eid=2-s2.0-84876309616\&partnerlD=40\&md5= 203d07daf1ab0a52bf5d2b472360c54c.

9. Bauman A, Crane M, Drayton BA, Titze S. The unrealised potential of bike share schemes to influence population physical activity levels - a narrative review. Prev Med (Baltim). 2017;103:S7-14. Academic Press Inc.

10. de Hartog JJ, Boogaard H, Nijland H, Hoek G. Do the health benefits of cycling outweigh the risks? Environ Health Perspect. 2010;118:1109-16.

11. Schepers P, Fishman E, Beelen R, Heinen E, Wijnen W, Parkin J. The mortality impact of bicycle paths and lanes related to physical activity, air pollution exposure and road safety. J Transp Health. 2015:2:460-73. Elsevier. Available from: http://linkinghub.elsevier.com/retrieve/pii/S221414051 5006842.

12. Wu Y, Rowangould D, London JK, Karner A. Modeling health equity in active transportation planning. Transp Res Part D Transp Environ. 2019:67:528-40.

13. Wade M. How riding to work is becoming a pursuit of the wealthy. Sydney: The Sydney Morning Herald; 2017.

14. Australian Bureau of Statistics. Method of Travel to Work (MTW15P) by Age (AGE10P) [Census TableBuilder]. 2016.

15. Australian Bureau of Statistics. Method of Travel to Work (MTW15P) by Sex (SEXP) [Census TableBuilder]. 2016.

16. Australian Bureau of Statistics. Method of Travel to Work (MTW15P) by Total Personal Income (INCP) [Census TableBuilder]. 2016

17. Beavis MJ, Moodie M. Incidental physical activity in Melbourne, Australia: health and economic impacts of mode of transport and suburban location. Heal Promot J Aust. 2014;25:174-81. 
18. Leigh-Hunt N, Bagguley D, Bash K, Turner V, Turnbull S, Valtorta N, et al. An overview of systematic reviews on the public health consequences of social isolation and loneliness. Public Health. 2017;152:157-71. https:// doi.org/10.1016/j.puhe.2017.07.035. Elsevier Ltd.

19. Rosano A, Loha CA, Falvo R, Van Der Zee J, Ricciardi W, Guasticchi $\mathrm{G}$, et al. The relationship between avoidable hospitalization and accessibility to primary care: a systematic review. Eur J Public Health 2013;23:356-60.

20. Geurs KT, van Wee B. Accessibility evaluation of land-use and transport strategies: review and research directions. J Transp Geogr. 2004;12:12740. Available from: http://linkinghub.elsevier.com/retrieve/pii/S0966 692303000607. Cited 2013 Oct 21.

21. Kent M, Karner A. Prioritizing low-stress and equitable bicycle networks using neighborhood-based accessibility measures. Int J Sustain Transp. 2019;13:100-10. Available from: https://www.tandfonline.com/action/ journallnformation?journalCode=ujst20.

22. Pucher J, Garrard J, Greaves S. Cycling down under: a comparative analysis of bicycling trends and policies in Sydney and Melbourne. $J$ Transp Geogr. 2011;19:332-45. Elsevier Ltd.

23. Rissel C, Wen LM. The possible effect on frequency of cycling if mandatory bicycle helmet legislation was repealed in Sydney, Australia: a cross sectional survey. Health Promot J Aust. 2011;22:178-83. Available from: http://www.ncbi.nlm.nih.gov/pubmed/22730946.

24. Hogg R, Quilter J. Policing mandatory bicycle helmet laws in NSW: fair cop or unjust gouge? Altern Law J. 2020;45:270-5.

25. Quilter J, Hogg RG. Over-the-top policing of bike helmet laws targets vulnerable riders. 2019. Report No.: 3983. Available from: https://ro. uow.edu.au/lhapapers/3983.

26. Garrard J, Greaves S, Ellison A. Cycling injuries in Australia: road safety's blind spot? J Australas Coll Road Saf. 2010;21:37-43.

27. Poulos RG, Hatfield J, Rissel C, Flack LK, Murphy S, Grzebieta R, et al. An exposure based study of crash and injury rates in a cohort of transport and recreational cyclists in New South Wales. Australia Accid Anal Prev. 2015;78:29-38.

28. Keoghan S. "The perfect storm": demand for e-bikes surges in Sydney amid pandemic. Sydney: The Sydney Morning Herald; 2020. Available from: https://www.smh.com.au/national/nsw/the-perfect-storm-demand-for-ebikes-surges-in-sydney-amid-pandemic-20200501-p54p1t.html.

29. Weatherzone. Sydney climate. 2021. Available from: http://www.weath erzone.com.au/climate/station.jsp. Cited 2021 Jan 4.

30. Australian Bureau of Statistics. Method of Travel to Work (MTW15P) by LGA (UR) and Sex (SEXP) [Census TableBuilder]. 2016.

31. City of Sydney. Cycling strategy and action plan. Sydney; 2018. Available from: https://www.cityofsydney.nsw.gov.au/strategies-actionplans/cycling-strategy-and-action-plan.

32. Lee RJ, Sener IN, Jones SN. Understanding the role of equity in active transportation planning in the United States. Transp Rev. 2017;37:21126. https://doi.org/10.1080/01441647.2016.1239660. Taylor \& Francis.

33. Cook KS, Hegtvedt KA. Distributive justice, equity, and equality. Annu Rev Sociol. 1983;9:217-41.

34. Rissel C, Greaves S, Wen LMLM, Capon A, Crane M, Standen C. Evaluating the transport, health and economic impacts of new urban cycling infrastructure in Sydney, Australia: protocol paper. BMC Public Health. 2013;13:1-8. Available from: http://www.ncbi.nlm.nih.gov/pubmed/ 24131667. Cited 2013 Nov 22.

35. Australian Institute of Health and Welfare (AlHW). The Active Australia Survey: a guide and manual for implementation, analysis and reporting. Canberra: AlHW: 2003.

36. Poulos RG, Hatfield J, Rissel C, Grzebieta R, McIntosh AS. Exposurebased cycling crash, near miss and injury rates: The Safer Cycling Prospective Cohort Study protocol. Inj Prev. 2012;18:1-4.

37. Greaves $\mathrm{S}$, Ellison AB, Ellison RB, Standen C. Development of online diary for longitudinal travel and activity surveys. In: Proc 93rd Annu Meet Transp Res Board. Washington, D.C.; 2014. Available from: http:// amonline.trb.org/trb-59976-2014-1.2467145/t-1112-1.2488871/378-1. 2490420/14-4834-1.2490446/14-4834-1.2490449? gr=1.

38. Bureau of Meteorology. Climate data online. 2017. Available from: http://www.bom.gov.au/climate/data/. Cited 2017 Jan 10.

39. ESRI. ArcGIS Network Analyst, computer software. Available from: https://www.esri.com/en-us/arcgis/products/arcgis-network-analyst/ overview. Cited 2021 May 7.
40. Google Inc. The Google Maps Directions API. 2021. Available from: https://developers.google.com/maps/documentation/directions/intro. Cited 2021 May 7.

41. Bureau of Transport Statistics. 2011 journey to work user guide. Sydney; 2014. Available from: http://www.bts.nsw.gov.au/ArticleDoc uments/84/TR2013-12_2011_JTW_User_Guide_v1_3.pdf.aspx.

42. Econometric Software Inc. NLOGIT6, computer software. 2016. Available from: http://www.limdep.com/.

43. Microsoft. Excel, computer software. 2021. Available from: https:// www.microsoft.com/en-au/microsoft-365/p/excel.

44. Parkin J, Rotheram J. Design speeds and acceleration characteristics of bicycle traffic for use in planning, design and appraisal. Transp Policy. 2010;17:335-41. https://doi.org/10.1016/j.tranpol.2010.03.001. Elsevier.

45. Train KE. Discrete choice methods with simulation. 2nd ed. Cambridge: Cambridge University Press; 2009.

46. de Jong G, Daly A, Pieters M, van der Hoorn T. The logsum as an evaluation measure: review of the literature and new results. Transp Res Part A Policy Pract. 2007;41:874-89. Available from: http://linkinghub.elsev ier.com/retrieve/pii/S0965856407000316. Cited 2014 Jan 13.

47. Transport for NSW. Principles and guidelines for economic appraisal of transport investment and initiatives. Sydney; 2013. Available from: https://www.transport.nsw.gov.au/newsroom-and-events/reportsand-publications/principles-and-guidelines-economic-appraisal-of

48. Tableau Software. Tableau Desktop, computer software. Seattle; 2020 Available from: https://www.tableau.com/.

49. Department of Health. Physical activity and exercise guidelines for all Australians. 2021. Available from: https://www.health.gov.au/healthtopics/physical-activity-and-exercise/physical-activity-and-exerciseguidelines-for-all-australians. Cited 2021 May 7.

50. Goel R, Goodman A, Aldred R, Nakamura R, Tatah L, Garcia LMT, ZapataDiomedi B, Herick de Sa T, Tiwari G, de Nazelle A, Tainio M, Buehler R, Götschi T, Woodcock J. Cycling behaviour in 17 countries across 6 continents: levels of cycling, who cycles, for what purpose, and how far? Trans Rev. 2021. https://doi.org/10.1080/01441647.2021.1915898.

51. Garrard J, Handy S, Dill J. Women and cycling. In: Pucher J, Buehler R, editors. City Cycl. Cambridge: The MIT Press; 2012. p. 211-34.

52. Garrard J, Conroy J, Winters M, Pucher J, Rissel C. Older adults and cycling. In: Buehler R, Pucher J, editors. Cycl Sustain Cities. Cambridge: MIT Press; 2021.

53. Garrard J. Women and cycling: Addressing the gender gap. In: Buehler R, Pucher J, editors. Cycl Sustain Cities. Cambridge: MIT Press; 2021.

54. Wardman M, Tight M, Page M. Factors influencing the propensity to cycle to work. Transp Res Part A Policy Pract. 2007;41:339-50. Available from: http://linkinghub.elsevier.com/retrieve/pii/S0965856406001212. Cited 2013 May 24.

55. Börjesson M, Eliasson J. The value of time and external benefits in bicycle appraisal. Transp Res Part A Policy Pract. 2012;46:673-83. Available from: http://linkinghub.elsevier.com/retrieve/pii/S0965856412000079. Cited 2014 May 12

56. Standen C, Crane M, Collins A, Greaves S, Rissel C. Determinants of mode and route change following the opening of a new cycleway in Sydney, Australia. J Transp Health. 2017:4:255-66.

57. Tranter P, Tolley R. Slow cities: conquering our speed addiction for health and sustainability. Elsevier Science; 2020. Available from: https:// books.google.com.au/books?id=2pLhDwAAQBAJ.

58. Ortúzar JDD, Willumsen LG. Modelling transport. 4th ed. Chichester: Wiley; 2011.

59. Department of Health. Australia's physical activity and sedentary behaviour guidelines and the Australian 24-hour movement guidelines. 2019.

60. Bull FC, Al-Ansari SS, Biddle S, Borodulin K, Buman MP, Cardon G, et al. World Health Organization 2020 guidelines on physical activity and sedentary behaviour. Br J Sports Med. 2020:1451-62. Available from: http://bjsm.bmj.com/. Cited 2021 May 6.

61. Australian Bureau of Statistics. 4324.0.55.001 - microdata: national health survey, 2017-18. 2019.

62. Nazzari H, Isserow SH, Heilbron B, Chb MB, McKinney J, Lithwick DJ, et al. The health benefits of physical activity and cardiorespiratory fitness. B C Med J. 2016;58:131-7.

63. Stappers NEH, Van Kann DHH, Ettema D, De Vries NK, Kremers SPJ. The effect of infrastructural changes in the built environment on physical activity, active transportation and sedentary behavior - a systematic 
review. Health Place. 2018;53:135-49. https://doi.org/10.1016/j.healt hplace.2018.08.002. Elsevier Ltd.

64. Sundfør HB, Fyhri A. A push for public health: the effect of e-bikes on physical activity levels. BMC Public Health. 2017;17:1-12. BMC Public Health.

65. Braveman $\mathrm{P}$, Arkin E, Orleans T, Proctor D, Plough A. What is health equity? And what difference does a definition make? Princeton; 2017. Available from: https://www.rwjf.org/en/library/research/2017/05/what-is-healthequity-html.

\section{Publisher's Note}

Springer Nature remains neutral with regard to jurisdictional claims in published maps and institutional affiliations.

- fast, convenient online submission

- thorough peer review by experienced researchers in your field

- rapid publication on acceptance

- support for research data, including large and complex data types

- gold Open Access which fosters wider collaboration and increased citations

- maximum visibility for your research: over $100 \mathrm{M}$ website views per year

At $\mathrm{BMC}$, research is always in progress.

Learn more biomedcentral.com/submissions 